\title{
Resistance to an optical illusion, figural after-effects, and field dependence
}

\author{
LUDWIG IMMERGLUCK 1 \\ SAN FRANCISCO STATE COLLEGE
}

The ability to resist geometric illusions is shown to be related both to measures of field independence and to figural after-effect potency. Ss who demonstrated figural after-effects on a particular task, in contrast to those who did not, were able to counteract a presented visual illusion and were also clearly identified as field-independent on a pertinent perceptual task. Consonant with the evidence of previously reported related studies, the present findings continue to show that individual differences in figural after-effect potency are systematically related to a wider gamut of perceptual and behavioral response categories.

Two recent investigations (Immergluck, 1966; Immergluck, 1966) demonstrated a close relationship between individual differences in figural after-effect performance and diverse other perceptual responses. More specifically, Ss who demonstrated figural after-effects on a particular task showed a considerably higher rate of figure ground reversal on a series of reversible figure tasks and were also clearly identified as "fieldindependent" on a Rod and Frame Test as contrasted with Ss who failed to exhibit after-effects, who showed at the same time low reversal amplitude and who were also clearly identifiable as "field-dependent." The results of both studies suggested strongly that the elemental neural processes which generate after-effects are related to a broader and possibly more complex nexus of other perceptual and behavioral categories.

The present investigation seeks to extend the examination of the relationship between figural after-effects and other areas of perceiving by exploring responses to geometric illusions. At first glance, the cogency of attempts to relate figural after-effect performance to optical illusion responses may not be apparent, but the justification for the selection of illusion tasks rests in the demonstrated superiority of Ss who show stronger after-effects to counteract distracting (or irrelevant) stimulus field forces (Immergluck, 1966). And since resistance to illusions is also predicated, at least to an extent, upon a S's ability to counter those contextual elements of a stimulus field (Crutchfield et al, 1958; McGurk, 1965) which elicit the illusory response, it is reasonable to assume that those Ss who demonstrate greater after-effect strength should also show greater ability to resist an illusion.

The major aims, then, of the study at hand are to test the hypotheses that (1) the strength of figural aftereffects is related to the ability to counter visual illusions, and (2) the ability to resist visual illusions is related to perceptual measures of field independence, i.e., field-independent Ss should be more successful in countering illusions than field-dependent ones. Method

The selection of the S groups, college students ranging in age from 19 to 22 years, was based on their performance on a Rod and Frame Test (cf., Witkin, 1954) designed to assess their degree of field dependence or field independence, respectively. Each $\mathrm{S}$ was exposed in an otherwise totally dark room to a slanted luminous rod surrounded by a tilted luminous square. Both rod and square (frame) could be tilted independently of each other at varying angles by the $\mathrm{E}$ and $\mathrm{S}$ was required to indicate the true vertical position of the rod while disregarding the various tilts of the surrounding frame. Typically, field-dependent Ss are greatly influenced by the tilted frame context and make correspondingly gross errors in their judgments of the rod's vertical position, while field-independent Ss are presumably not so bound by the distracting context of the stimulus field, and, able to disregard the varying tilts of the surrounding frame, can designate the vertical position of the rod with great accuracy. As in the previously reported studies, Ss who were able to place the rod consistently within $3^{\circ}$ of its true vertical position were assigned to the field-independent group, while those who made consistent errors of $10^{\circ}$ or more were placed in the field-dependent category. By this method the final $\mathrm{S}$ groups of 32 field-independent and 24 field-dependent Ss were established.

All Ss were then exposed individually to a figural after-effect task and to an optical illusion task. In the former, the I Figure consisted of two different sized squares, one measuring 1.5 in., the other 1 in., separated from a central fixation point by 2 in. from their respective centers. Following a fixation time of $30 \mathrm{sec}$. the T Figure, consisting of two identical squares, 1.5 in., also separated by 2 in. from a central inspection point,

Table 1. A Comparison of Responses to the Zolliner Illusion by Subjects Who Showed Figural After-effects and Subjects Who Showed No After-effects

\begin{tabular}{lrc} 
& \multicolumn{2}{c}{ Zöllner Illusion $^{*}$} \\
\hline After-effect & - & + \\
No After-effect & 21 & 11 \\
& 7 & 17 \\
& & $x^{2}=7.29$ \\
& $p<0.01$ \\
\hline
\end{tabular}

* The (-) column indicates the number of Subjects who resisted the illusion and the $(+)$ column those who gave illusion responses. 
Table 2. A Comparison of Responses to the Zöllner Illusion for Field Independent and Field Dependent Subjects

\begin{tabular}{lrc} 
& \multicolumn{2}{c}{ Zöliner Illusion* } \\
\hline & - & + \\
\hline Field Independent Subjects & 22 & 10 \\
Field Dependent Subjects & 7 & 17 \\
& & $X^{2}=8.60$ \\
& $P \quad<0.01$ \\
\hline
\end{tabular}

* (-) designated those Subjects who resisted the illusion and (+) those who gave illusion responses.

was immediately presented and the $S$ was asked to determine whether the T Figure squares appeared to be "equal" or "unequal" in size. The operation of the after-effect is demonstrated by $S$ 's perception of the identical T Figure squares as "unequal."

The well known Zolliner's illusion, consisting of four objectively parallel vertical lines, each in a "herringbone" context of short slanted lines, constituted the optical illusion task. After an exposure time of $5 \mathrm{sec}$., the $S$ was asked to reproduce only the vertical lines exactly as he perceived them. In addition to the reproductions, his verbal responses regarding his perception of the lines as either "parallel" or "slanted" were solicited. ${ }^{2}$ The ability to reproduce and to perceive the lines as "parallel" constituted the index of S's ability to counter the illusion.

\section{Results and Discussion}

Table 1 demonstrates a clear relationship $(p<0.01)$ between Ss' performance on the figural after-effect task and their ability to counter an illusion. The hypothesis that field-independent Ss are more successful in countering the contextual factors inherent in an optical illusion than are field-dependent ones is also clearly supported by the present data (cf., Table 2), and once again, these findings show, as did the results of related previous investigations, a close relationship $(p<0.001)$ between the potency of after-effects and measures of field-dependence (cf., Table 3).

The present findings underscore the contention that illusions-even of a type widely used in demonstrations of such phenomena-are not as ubiquitous as has often been assumed. Indeed, there are wide individual differences in the perception of these types of stimuli and, furthermore, individual differences in the ability to

Table 3. A Comparison Between Field-Independent and FieldDependent Subjects in Figural After-effect Performance

\begin{tabular}{lcc} 
& After-effect & No After-effect \\
\hline Field-Independent Subjects & 25 & 7 \\
Field-Dependent Subjects & 6 & 18 \\
& & $X^{2}=18.88$ \\
& p $<0.001$ \\
\hline
\end{tabular}

counter those forces inherent in the stimulus field which give rise to an illusory percept are closely related to other perceptual skills and processes, among which are apparently those neural processes which are involved in the generation of after-effects. The specific finding that Ss who demonstrated figural after-effects were able to counter the presented illusion while those who failed to demonstrate these effects were caught, as it were, by the illusion, is of particular interest in the light of a recently reported study by Ganz (1966) in which the proposition is presented that the effectiveness of aftereffects depends on the same processes which give rise to visual illusions. After-effect phenomena, in other words, are essentially instances of optical illusions. But if this were the case, the results of the present study should have been exactly the opposite of those obtained, i.e., Ss demonstrating after-effects should also have shown a high incidence of illusion responses. While the present study constitutes in no sense a direct replication of the experimental conditions pertaining to Ganz's investigation (nor was it intended as such), the results show nonetheless that at least in the case of the Zollner illusion-and at that an illusion which is by no means untypical of such perceptual phenomena-the proposition that after-effects are in essence an expression of "simultaneous illusions" is not supportable. In fact, the data at hand lend support to the contention that the processes giving rise to figural after-effects enable a subject to counteract the distorting pulls of a stimulus field, such as is the case in optical illusions, and once more individual differences in figural aftereffect potency emerge as relevant variables which are systematically related to a wider gamut of diverse perceptual and behavioral response categories.

\section{References}

Crutchfield, R. S., Woodworth, D. G., \& Albrecht, R. C. Perceptual performance and the effective person. Personnel Lab. Rep., WADC-TN-58-60, ASTIA Doc. No. 131039, Lackland AFB, Texas, 1958.

Ganz, L. Mechanisms of the figural after-effects. Psychol. Rev., $1966,73,128-150$.

Immergluck, $\mathbf{L}$. Visual figural after-effects and field dependence. Psychon. Sci., 1966, 4 (6), 219-220.

Immergluck, L. Figural after-effects, rate of "figure-ground" reversal, and field dependence. Psychon. Sci., 1966, 6 (2), 45-46.

McGurk, E. Susceptibility to visual illusions. J. Psychol., 1965, 61, 127-143.

Witkin, H. A., Lewis, H. B., Hertzman, M., Machover, K., Meissner, P. B., \& Wapner, S. Personality through perception. New York: Harper, 1954.

\section{Notes}

1. This study was supported by a San Francisco State College faculty research fund, under the auspices of the National Science Foundation Institutional Grant.

2. In each instance, those subjects whose drawn reproductions showed the lines to be parallel also indicated verbally that they perceived them as such. 